\title{
QUALIDADE MICROBIOLÓGICA DE PLANTAS MEDICINAIS CULTIVADAS EM HORTAS DOMÉSTICAS
}

\section{MICROBIOLOGICAL QUALITY OF MEDICINAL PLANTS IN DOMESTIC GARDENS}

\author{
Nhara Soraya Paganela Marcondes*, Luís Antônio Esmerino** \\ * Departamento de Ciências Farmacêuticas, Laboratório de Farmacognosia, \\ Universidade Estadual de Ponta Grossa, UEPG. E-mail: nharaso@uepg.br \\ ** Departamento de Análises Clínicas, Laboratório de Microbiologia Clínica, \\ Universidade Estadual de Ponta Grossa, (UEPG). E-mail: esmerino@uepg.br
}

Recebido para publicação em 12/07/2010

Aceito para publicação em 22/09/2010

\begin{abstract}
RESUMO
A avaliação da qualidade microbiológica de plantas medicinais é uma importante etapa no que se refere ao aspecto de segurança ao usuário. No Brasil a legislação vigente menciona a pesquisa de contaminantes microbiológicos. O objetivo do presente trabalho foi avaliar a carga microbiana presentes em plantas medicinais provenientes das hortas domésticas de um bairro da cidade de Ponta Grossa, Paraná. Nosso estudo mostrou a presença de bactérias aeróbias mesófilas em todas as amostras com carga variando de $6,3 \times 10^{2}$ a $2,32 \times 10^{5} \mathrm{UFC} / \mathrm{g}$. Em $73 \%$ das plantas foram detectados coliformes totais e em $27 \%$ detectou-se coliformes $45^{\circ} \mathrm{C}$. O tratamento térmico simulando a preparação de um infuso ou chá reduziu significativamente

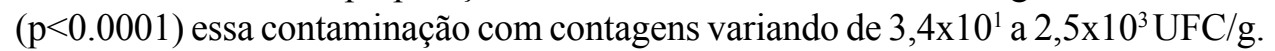
Todavia, em $18 \%$ das amostras essa redução não foi satisfatória e a carga microbiana se apresentou superior aquela estabelecida na legislação vigente para uso por via oral $\left(1,0 \times 10^{3}\right)$, entretanto, essas amostras não apresentaram coliformes $45^{\circ} \mathrm{C}$. Esses dados mostram e reforçam a necessidade de uma educação e orientação no uso de plantas medicinais para que a contaminação microbiana possa ser reduzida e não apresentar risco à saúde.
\end{abstract}

Palavras-chave: Drogas vegetais. Plantas medicinais. Qualidade microbiana.

\begin{abstract}
Microbiological quality evaluation of medicinal plants is an important aspect to provide user safety. In Brazil, the legislation mentions microbiological contamination research. The aim of this study was to evaluate the microbial load of medicinal plants in home gardens in one of the city districts of Ponta Grossa, Parana. The study showed the presence of mesophilic aerobic bacteria inall samples with a load ranging from 6.3 to $2.32 \times 102 \times 105 \mathrm{CFU} / \mathrm{g}$. In $73 \%$ of the plants it was detected the presence of total coliform; and in $27 \%$ of the plants the presence of coliform
\end{abstract}


$45^{\circ} \mathrm{C}$. Heat treatment simulating the preparation of an infusion or tea significantly reduced $(\mathrm{p}<0.0001)$ this contamination with counts ranging from 3.4 to $2.5 \mathrm{X} 101$ $\mathrm{x} 103 \mathrm{CFU} / \mathrm{g}$. However, in $18 \%$ of the samples this reduction was not satisfactory and the microbial load was higher than that permitted in the current legislation $(1.0 \times 103)$ for oral use. However, these samples did not present coliform $45^{\circ} \mathrm{C}$. The data demonstrate and reinforce the need for education and guidance in the use of medicinal plants so that microbial contamination can be reduced and not pose a risk for health.

Keywords: Herbal drugs. Medicinal plants. Microbial quality.

\section{Introdução}

O aumento no consumo de drogas vegetais transformou seu uso em um problema de Saúde Pública, devida à possibilidade de acesso a produtos sem as adequadas condições de uso. A preocupação com a qualidade é principalmente devida ao potencial de contaminação microbiana devido à sua origem natural (BUGNO et al., 2005).

As drogas vegetais, normalmente, apresentam elevada carga microbiana, quer seja saprófita ou patogênica. Os microrganismos contaminantes, normalmente, são provenientes do solo, da água e do ar. A contaminação secundária pode ainda ocorrer devido às práticas de agricultura inadequada, ao armazenamento e ao processamento (SANTOMI et al., 2005). A contaminação por bactérias e fungos, além de apresentar risco à saúde dos usuários, pode levar a destruição e/ou alteração dos princípios ativos ou ocasionar a produção de substâncias tóxicas, como as aflatoxinas e micotoxinas produzidas por várias espécies de fungos (OLIVEIRA et al.,1991).

Estudos sobre a qualidade microbiológica de plantas medicinais mostraram carga microbiana com resultado diverso. Furlaneto et al. (2003) analisaram amostras de drogas vegetais comercializadas livremente nas ruas da cidade de Londrina - PR, e observaram cargas de microrganismos aeróbios mesófilos viáveis variando de $1,0 \times 10^{3}$ a $1,0 \times 10^{7} \mathrm{UFC} / \mathrm{g}$. Os autores concluíram que as drogas vegetais testadas estavam em condições de qualidade sanitária precárias para o consumo, indicando condições insatisfatórias de armazenamento e comercialização. Zaroni et al. (2004) analisaram 72 amostras de plantas medicinais, enviadas por produtores do Estado do Paraná. Os resultados das análises microbiológicas mostraram que $79 \%$ não atendiam os parâmetros estabelecidos pela OMS, tanto para utilização da planta medicinal na forma de chá ou para uso interno. Bugno et al. (2005) avaliando a contaminação microbiana presente em drogas vegetais, na cidade de São Paulo - SP, observaram percentuais de alterações em 93,2\% das plantas analisadas e sugerem a necessidade de medidas educacionais que garantam a qualidade destes produtos.

Na determinação da qualidade microbiológica de chás de Cymbopogon citratus (capim-limão), Gomes et al. (2008) detectaram a presença de coliformes a $35^{\circ} \mathrm{C}$ em $50 \%$ das amostras analisadas, em três amostras foi observado a presença de coliformes a $45^{\circ} \mathrm{C}$, com presença de Escherichia coli em uma amostra. Após o preparo dos infusos a carga microbiana foi negativa.

Chimin et al (2008) avaliando a qualidade de amostras comerciais de Maytenus ilicifolia (espinheira-santa), comercializadas no Estado do Paraná, observaram carga bacteriana dentro dos limites estabelecidos para plantas que passarão por tratamento que pode reduzir o número de microrganismos como o uso de água fervente, indicando, dessa forma, que as amostras não apresentavam problemas de contaminação microbiana que pudesse inviabilizar o seu uso como medicamento.

Assim, avaliações da qualidade sanitária de plantas medicinais constituem uma importante etapa no que se refere ao aspecto de segurança, principalmente pelo fato de serem utilizadas geralmente por idosos, crianças e pessoas debilitadas (SATOMI et al., 2005). Com base no exposto acima, o objetivo do presente estudo foi avaliar a qualidade microbiológica de plantas medicinais rasteiras, cultivadas 
em hortas domésticas; determinar a carga microbiana presente nas plantas medicinais, antes de se preparar o infuso ou chá, através da determinação de bactérias aeróbias mesófilas, coliformes fecais e coliformes $45^{\circ} \mathrm{C}$; determinar a carga de bactérias aeróbias mesófilas após o preparo do infuso ou chá e comparar com a carga antes do preparo.

\section{Material e Métodos}

\section{Coleta e preparo das amostras}

Esse trabalho foi realizado com 22 amostras de plantas medicinais, utilizadas para preparação de infusos e chás destinados ao uso por via oral. Foi solicitado para que os participantes da pesquisa fornecessem em um saco plástico estéril duas amostras da mesma planta de suas hortas domésticas e as preparasse como se fossem utilizadas para se fazer uma dose de chá ou infuso. As amostras fornecidas foram acondicionadas em caixa de isopor contendo gelo reciclável e encaminhadas imediatamente ao laboratório de microbiologia da Universidade Estadual de Ponta Grossa (UEPG) onde foram processadas.

O material analisado foi constituído por drogas "in natura" e pelos infusos preparados a partir das mesmas. O estudo abrangeu as espécies vegetais denominadas de Salvia officinalis L. (salvinha), Mentha spp.(hortelã), Mentha pulegium L. (poejoque é uma espécie de hortelã), Artemísia absinthium L. (losna), Melissa officinalis L. (cidró), Phyllanthus niruri L. (quebra-pedra) e Euphorbia prostata Ait. (quebra-pedra rasteira). No laboratório as duas amostras foram transferidas assepticamente para diferentes sacos plásticos, previamente tarados, com fechamento hermético. As amostras foram pesadas e em seguida, adicionou-se em um saco plástico 100 $\mathrm{mL}$ de diluente (água destilada estéril). Esses sacos plásticos foram agitados manualmente, cerca de 50 vezes, por aproximadamente dois minutos, sendo as amostras massageadas com as mãos, por fora dos sacos, tomando-se os devidos cuidados para que as protuberâncias ou pontas não furassem a embalagem plástica. Essa técnica conhecida como de lavagem superficial ou enxagüadura foi utilizada para obtenção dos microrganismos presentes nas plantas medicinais e foi adaptada da análise de alimentos (SILVA et al., 2007). No outro saco plástico adicionou-se $100 \mathrm{~mL}$ de água fervente, deixou-se agir por 10 minutos. Esse procedimento simulou o preparo do infuso ou chá.

Os caldos obtidos foram transferidos para um frasco erlenmeyer esterilizado. Esses caldos, chamado de caldo de lavagem ou caldo de enxagüadura e o infuso ou chá foram utilizados para as análises microbiológicas posteriores e foram considerados como sendo diluídos $1 / 10\left(10^{-1}\right)$ e na seqüência foram diluídos a $10^{-2}$ e $10^{-3}$. Estabeleceu-se que os dois grupos de amostras fossem denominados de sem e com tratamento térmico.

\section{Procedimentos microbiológicos}

Para a determinação de microrganismos mesófilos aeróbios o meio de cultura utilizado foi o Tryptone Soya Agar (TSA), e a técnica utilizada foi a de semeadura em profundidade (SILVA et al., 2007).

As amostras foram analisadas pipetando-se alíquotas de $1,0 \mathrm{~mL}$ das diluições $10^{-1}, 10^{-2}$ e $10^{-2}$ para placas de Petri esterilizadas. Em seguida foram vertidos assepticamente $19 \mathrm{~mL}$ do meio TSA previamente fundido e resfriado a $44-46{ }^{\circ} \mathrm{C}$. As placas foram homogeneizadas e incubadas invertidas em estufas a $35^{\circ} \mathrm{C}$ por $24-48$ horas. Transcorrido o tempo de incubação contou-se as unidades formadoras de colônias (UFC) com o auxílio de um contador de colônias (Biomatic ${ }^{\circledR}$ ). Foram consideradas para contagem preferencialmente as placas que apresentaram número entre 25 e 250 colônias e multiplicou-se o número de UFC pelo respectivo fator de diluição. Os resultados foram expressos em UFC/g (Unidades Formadoras de Colônias/ 1,0 grama) considerando o peso inicial das amostras.

O número mais provável $(\mathrm{NMP} / \mathrm{g})$ de coliformes totais e coliformes termotolerantes $\left(45^{\circ} \mathrm{C}\right)$ foi determinado pela técnica dos tubos múltiplos em uma série de três tubos e foi realizado o teste presuntivo e o confirmatório (SILVA et al., 2007). Para o teste presuntivo utilizou-se o Caldo Lauril Sulfato Triptose (LST) acrescentado de púrpura de 
bromocresol, na concentração de $0,001 \%$ e com tubos de Duhran invertidos.

Para o teste confirmativo de coliformes totais foi utilizado o Caldo Lactosado Verde Brilhante (Bile 2\%) e para o teste confirmativo de coliformes $45^{\circ} \mathrm{C}$ utilizou-se o Caldo Escherichia coli. A determinação de coliformes totais e coliformes $45^{\circ} \mathrm{C}$ por grama $(\mathrm{NMP} / \mathrm{g})$ nas amostras foi feita através de tabela apropriada às diluições inoculadas (SILVA et al., 2007).

Análise estatística com aplicação dos testes ANOVA e Tukey $(p<0.05)$ foi realizada comparando as contagens das UFC/g dos microrganismos aeróbios mesófilos nas plantas estudadas, sem e com tratamento térmico, utilizando o programa GraphPad InStat ${ }^{\circledR}$.

\section{Resultados e discussão}

Os valores obtidos nas contagens de microrganismos aeróbios mesófilos em UFC/g estão representados na Tabela 1 . A contagem desses microrganismos nas plantas medicinais analisadas, sem tratamento térmico, mostrou contagens variando de $6,3 \times 10^{2}$ a $2,32 \times 10^{5} \mathrm{UFC} / \mathrm{g}$. A planta medicinal losna apresentou a maior carga microbiana, seguida das de hortelã. Entretanto nem todas as amostras de hortelã apresentaram carga microbiana elevada,

Tabela 1 - Resultados obtidos na determinação dos microrganismos

\begin{tabular}{|c|c|c|c|c|}
\hline \multirow[b]{2}{*}{ AMOSTRAS } & \multicolumn{3}{|c|}{$\begin{array}{c}\text { SEM TRATAMENTO } \\
\text { TÉRMICO }\end{array}$} & \multirow{2}{*}{$\begin{array}{c}\text { COM TRATAMENTO } \\
\text { TÉRMICO } \\
\text { Aeróbias } \\
\text { Mesófilas } \\
\text { UFC/g }\end{array}$} \\
\hline & $\begin{array}{c}\text { Aeróbias } \\
\text { Mesófilas } \\
\text { UFC/g }\end{array}$ & $\begin{array}{c}\text { Coliformes } \\
\text { Totais } \\
\text { NMP/g }\end{array}$ & $\begin{array}{c}\text { Coliformes } \\
45^{\circ} \mathrm{C} \\
\mathrm{NMP} / \mathrm{g}\end{array}$ & \\
\hline Salvia officinalis L. (salvinha) & $2,03 \times 10^{3}$ & $<3,0$ & $<3,0$ & $2,89 \times 10^{2}$ \\
\hline Mentha spp.(hortelã) & $6,29 \times 10^{2}$ & $5,1 \times 10^{1}$ & $4,3 \times 10^{1}$ & $4,90 \times 10^{2}$ \\
\hline Mentha pulegium L. (poejo) & $8,08 \times 10^{2}$ & $2,85 \times 10^{1}$ & $<3,0$ & $9,1 \times 10^{1}$ \\
\hline Mentha spp.(hortelã) & $2,94 \times 10^{4}$ & $1,19 \times 10^{2}$ & $<3,0$ & $2,5 \times 10^{2}$ \\
\hline Mentha spp.(hortelã) & $2,18 \times 10^{5}$ & $2,36 \times 10^{1}$ & $<3,0$ & $3,4 \times 10^{1}$ \\
\hline Artemísia absinthium L. (losna) & $2,32 \times 10^{5}$ & $<3,0$ & $<3,0$ & 0,0 \\
\hline Melissa officinalis L. (cidró) & $3,87 \times 10^{4}$ & $<3,0$ & $<3,0$ & 0,0 \\
\hline Phyllanthus niruri L. (quebra-pedra) & $3,33 \times 10^{3}$ & $1,71 \times 10^{2}$ & $1,71 \times 10^{2}$ & $5,33 \times 10^{2}$ \\
\hline Mentha spp.(hortelã) & $4,88 \times 10^{3}$ & $5,41 \times 10^{1}$ & $<3,0$ & $2,1 \times 10^{3}$ \\
\hline Mentha spp.(hortelã) & $6,42 \times 10^{3}$ & $1,25 \times 10^{3}$ & $<3,0$ & $2,5 \times 10^{3}$ \\
\hline $\begin{array}{l}\text { Euphorbia prostata Ait. } \\
\text { (quebra-pedra rasteira) }\end{array}$ & $2,81 \times 10^{3}$ & $1,0 \times 10^{2}$ & $1,0 \times 10^{2}$ & $2,5 \times 10^{2}$ \\
\hline PARÂMETRO & & & & $\leq 10^{3} \mathrm{UFC} / \mathrm{g}$ \\
\hline
\end{tabular}

inclusive uma das amostras foi a que apresentou a menor contaminação bacteriana.

A contagem total de aeróbios mesófilos em placas é utilizada como indicador geral de populações bacterianas. O método não diferencia os tipos de bactérias, sendo utilizado para se obter informações gerais sobre a qualidade de produtos, porque populações altas de bactérias podem indicar deficiência ou baixa condição higiênico-sanitária (SILVA et al., 2007).

Segundo Gomes et al. (2008) as drogas vegetais são também passíveis de contaminação microbiana, exigindo cuidados especiais durante a sua manipulação. Os cuidados vão desde o plantio, passa pela comercialização e vão até a sua utilização como infuso ou chá. Quando as condições higiênico-sanitárias não são adequadas, gera-se um produto de má qualidade, que poderá veicular vários microrganismos patogênicos. Dentre os principais microrganismos potencialmente patogênicos encontrados em vegetais estão os associados à contaminação fecal. Dessa forma é importante a pesquisa dessas bactérias em plantas medicinais utilizadas para o preparo de infusos ou chás.

A determinação de coliformes totais, realizada pelo método do Número Mais Provável (NMP) detectou a presença em $72,7 \%$ das amostras. A contagem variou de $<3,0$ a $1,25 \times 10^{3} \mathrm{NMP} / \mathrm{g}$, com contagem média de $1,44 \times 10^{2} \mathrm{NMP} / \mathrm{g} \pm 3,68 \times 10^{-2}$ $\mathrm{NMP} / \mathrm{g}$. As maiores cargas de coliformes totais foram observadas nas amostras de hortelã, e as menores contagens foram observadas nas amostras de salvinha, losna e cidró.

Segundo Silva et al. (2007) o grupo dos coliformes totais é um subgrupo da família Enterobacteriaceae. Nesse grupo estão presentes as enterobactérias capazes de fermentar a lactose com produção de gás, em 24/48 horas a $35^{\circ} \mathrm{C}$. Cerca de 20 espécies representam o gru- 
po, dentre as quais são encontradas tanto bactérias originárias do trato gastrintestinal de humanos como de outros animais de sangue quente como também bactérias não entéricas como espécies de Citrobacter, Enterobacter, Klebsiella e Serratia, dentre outras.

A determinação de coliformes $45^{\circ} \mathrm{C}$ detectou a presença em $27,3 \%$ das amostras analisadas. A contagem variou de $<3,0$ a $1,71 \times 10^{2} \mathrm{NMP} / \mathrm{g}$, com média de $2,5 \times 10^{1} \pm 3,68 \times 10^{2} \mathrm{NMP} / \mathrm{g}$. Nesse grupo as amostras de quebra-pedra apresentaram as maiores cargas. $\mathrm{O}$ grupo dos coliformes a $45^{\circ} \mathrm{C}$, anteriormente chamados de coliformes fecais, é um subgrupo dos coliformes totais, restrito aos membros capazes de fermentar a lactose em 24 horas a 44,5-45,5 ${ }^{\circ} \mathrm{C}$, com produção de gás. Essa definição objetivou, em princípio, selecionar apenas enterobactérias originários do trato gastrintestinal (Escherichia coli), porém, atualmente sabe-se que o grupo inclui membros de origem não fecal como: várias cepas Klebsiella pneumoniae, Pantoea agglomerans, Enterobacter aerogenes, Enterobacter cloacae e Citrobacter freundii (SILVA et al., 2007).

A análise estatística foi realizada comparando as contagens de UFC/g dos microrganismos aeróbios mesófilos, sem e com o tratamento térmico. Para a análise estatística os valores de NMP/g foram convertidos em $\log _{10}$ e utilizou-se o programa GraphPad InStat ${ }^{\circledR}$. A carga microbiana presente no caldo sem o tratamento térmico apresentou média de $4,9 \times 10^{-4} \pm 8,8 \times 10^{-4} \mathrm{UFC} / \mathrm{g}$ e foi significativamente maior ( $\mathrm{p}<0.0001)$ que a observada na mesma planta após o preparo do infuso (com o tratamento térmico) com média de $6,13 \times 10^{-2} \pm 8,55 \times 10^{-2} \mathrm{UFC} / \mathrm{g}$.

Com base na Legislação vigente podemos observar que em $82 \%$ das plantas medicinais analisadas, antes do tratamento térmico apresentam contaminação microbiana superior à estabelecida pela Resolução RDC n ${ }^{\circ} 48$. O tratamento térmico para o preparo dos infusos ou chás reduziu significativamente $(\mathrm{p}<0.0001)$ esta contaminação, entretanto em $18 \%$ das plantas estudadas o tratamento térmico não foi satisfatório e a contagem de microrganismos aeróbios mesófilos foi superior a $10^{3} \mathrm{UFC} / \mathrm{g}$ (Tabela 1), entretanto essas amostras não apresentaram coliformes a $45^{\circ} \mathrm{C}$.
Araujo e Ohara (2000) avaliaram a qualidade microbiológica de drogas vegetais comercializadas em feira de São Paulo e também, foram realizados testes para a avaliação da qualidade dos infusos preparados a partir dessas drogas. Nas drogas vegetais, foram determinadas cargas de microrganismos aeróbios mesófilos viáveis totais variando de $5,0 \times 10^{2}$ a $2,6 \times 10^{8} \mathrm{UFC} / \mathrm{g}$. Essa carga microbiana foi superior a que observamos em nosso estudo (Tabela 1). A preparação dos infusos resultou em diminuição expressiva do número de contaminantes aeróbios mesófilos, mas não na sua eliminação total, resultado semelhante ao que observamos em nosso estudo. $\mathrm{O}$ estudo sugere que, apesar da baixa qualidade sanitária das drogas vegetais, com a adição de água em ebulição podem ser obtidos infusos relativamente seguros.

Tradicionalmente os infusos e chás de plantas medicinais têm sido bastante utilizados como alternativa terapêutica das populações de baixa renda, porém nos últimos anos, o uso destas substâncias tem apresentado significativo aumento. Entre as várias razões que propiciaram o interesse da população pelas plantas medicinais podemos destacar a preferência dos consumidores por terapias naturais; preocupação em relação aos efeitos colaterais freqüentemente observados com os medicamentos sintéticos e a crença muita vez errônea de que os medicamentos fitoterápicos não possuem efeitos adversos. Além disso, os menores custos das drogas vegetais; e a existência de estudos científicos para alguns fitoterápicos comprovando sua eficácia clinica são também relatados como fatores que vem aumentado a utilização de drogas vegetais.

\section{Conclusão}

Esse estudo mostrou contaminação por microrganismos em plantas medicinais fornecidas pelos seus usuários e cultivadas em suas hortas domésticas. $O$ tratamento térmico simulando o preparo de um infuso ou chá reduziu significativamente essa contaminação, mas não a sua eliminação total. Muitos dos consumidores de infusos e chás cultivam as plantas medicinais em suas hortas domiciliares 
e muita vez esse cultivo e a manipulação na hora do preparo do chá é realizada em baixa condição higiênico-sanitária o que pode acarretar risco à saúde. Esses dados mostram e reforçam a necessidade de uma educação e orientação continuada no uso de plantas medicinais para que a contaminação microbiana possa ser reduzida e não apresentar risco à saúde.

\section{REFERÊNCIAS}

ARAÚJO, A. L.A.; OHARA, M.T. Qualidade microbiológica de drogas vegetais comercializadas em feira de São Paulo e de infusos derivados. Rev. bras. Cienc. Farm. v.36, n.1, p:129-37, 2000.

BRASIL. Resolução RDC n 48, de 16 de março de 2004. Dispõe sobre o registro de medicamentos fitoterápicos. Diário Oficial [da] República Federativa do Brasil, Brasília, DF, 18 mar. 2004.

BUGNO, A.; BUZZO, A. A.; NAKAMURA, C. T.; PEREIRA, T. C.; MATOS, D.; PINTO, T. J. A. Avalição da contaminação microbiana em drogas vegetais. Rev. bras. cienc. farm. v.41, n.4, p:491-497, 2005.

CHIMIN, A.; LIMA, E. L.; BELTRAME, F. L..; PEREIRA, A. V.; ESMERINO, L. A. Avaliação da Qualidade de Amostras Comerciais de Maytenus ilicifolia (espinheira-santa) Comercializadas no Estado do Paraná. Lat. Am. J. Pharm. v.27, n.4, p. 591-7, 2008.

FURLANETO, L.; MARINS, V.; ENDO, R. Qualidade microbiológica de drogas vegetais comercializadas nas ruas da cidade de Londrina/PR e de seus infusos. Saúde em revista, v. 5, n.10, p. 49-52, 2003.

GOMES, E. C. NEGRELLE, R. R. B.; ELPO, N. R. S. Determinação da qualidade microbiológica e físico-química de chás de Cymbopogon citratus (D.C) Stapf (capim-limão) Acta Sci. Health Sci. Maringá, v. 30, n. 1, p. 47-54, 2008

OLIVEIRA, F; AKISUE, G.; AKISUE, M. K. Farmacognosia. São Paulo: Atheneu, 1991. 426p.

SATOMI, L. C.; SORIANI, R. R.; PINTO, T. J. A. P. Descontaminação de drogas vegetais empregando irradiação gama e óxido de etileno: aspectos microbianos e químicos. Rev. bras. cienc. farm., v. 41, n.4, p.445-450, 2005.

SILVA, N.; JUNQUEIRA, V. C. A; SILVEIRA, N. F. A.; TANIWAKI, M. H.; SANTOS, R. F. S.; GOMES, R. A. R. Manual de métodos de análise microbiológica de alimentos. 3. ed. São Paulo: Varela, 2007. 536 p.
ZARONI, M.; PONTAROLO, R.; ABRAHÃO, W. S. M.; FÁVERO, M. L. D; CORREA JÚNIOR, C.; STREMEL, D. P. Qualidade microbiológica das plantas medicinais produzidas no Estado do Paraná 29 Rev. Bras. Farmacogn., v. 14, n. 1, jan.-jun. 2004. 